\title{
Direito, Estado e economia globalizada: as patentes de biotecnologia e o risco de privatização da biodiversidade
}

\author{
Ana Chenatia Thenio Oraf
}

Mestranda em Direito das Relações Sociais do Programa de Pós-Graduação em Direito da UFPR.

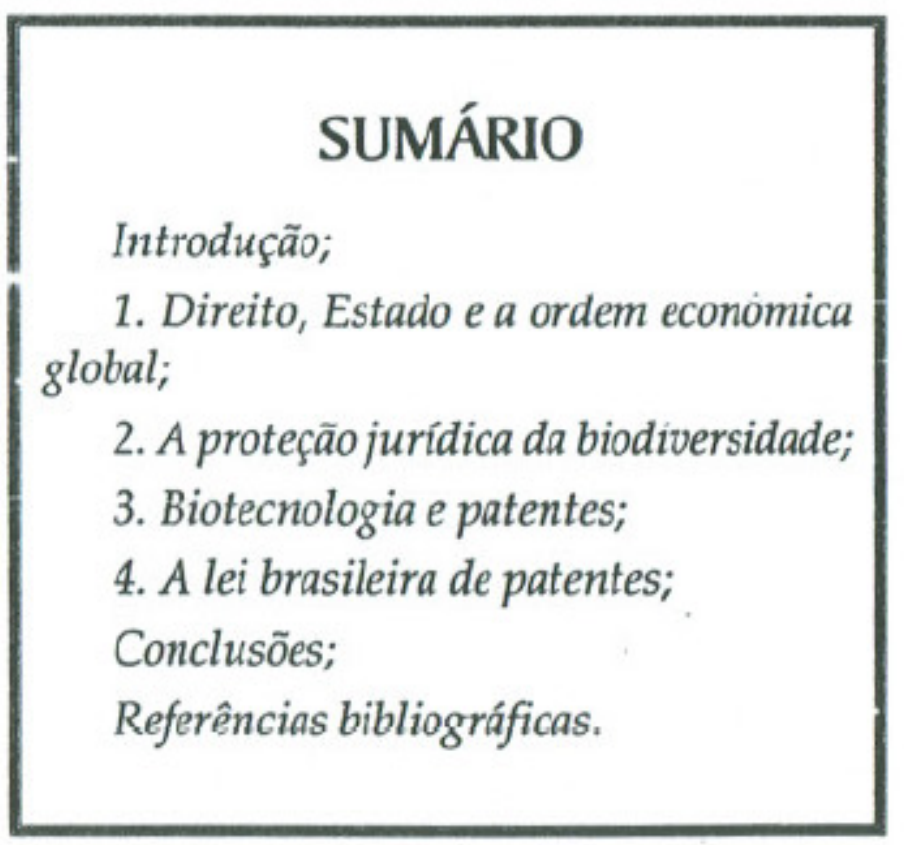

\section{SUMÁRIO}

rodução; global;

2. A proteção jurídica da biodiversidade;

3. Biotecnologia e patentes;

4. A lei brasileira de patentes;

Conclusoes;

Referências bibliográficas.

\section{Introdução}

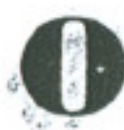

desenvolvimento do tema proposto

demanda uma análise funcional do

Direito e, uma perspectiva crítica de sua dogmática. Por outro lado, o contexto em que ele se insere compreende a hegemonia do modelo econômico neoliberal - tanto em termus giubais, quantic nacionais - que, nos dias de hoje, implica um redimensionamento do conteúdo de noçöes como "Estado Nacional", "soberania" e "poder político", ao mesmo tempo em que promove uma mitificação da ordem jurídica, em especial, dos direitos fundamentais.

Por se tratar de assunto recente, que não prescinde de uma abordagem interdisciplinar, buscar-se-á traçar um panorama de seus tópicos mais polêmicos em cotejo com os balizamentos impostos pela Constituiçăo brasileira de 1988 e, com a legislaçẳo ordinária incidente, procurando 
demonstrar as perplexidades que ele certamente provoca.

\section{Direito, Estado e a ordem econômica global}

O Direito não se limita a um conjunto de normas, é uma prática social que integra uma ordem política ${ }^{1}$ e que é também fruto de uma cultura determinada. ${ }^{2} \mathrm{~A}$ crescente complexidade da realidade socioeconômica tem imposto uma multiplicidade de regras que são quase sempre parciais, mutáveis, contraditórias e contingenciais. Nas palavras de JOSÉ EDUARDO FARIA:

"Fruto de uma economia em fase de globalização, de uma sociedade cada vez mais diferenciada e de um Estado obrigadoa desempenhar tarefas múltiplas e por vezes até mesmo contraditórias, esse novo sistema normativo cresceu e se consolidou a partir de uma tensa e intrincada pluralidade de pretensões materiais. A distinção entre interesses privados e interesses comuns e coletivos, fundamental para a antiga engenharia jurídico-política liberal-burguesa, já não é mais entâo capaz de ocultar que, na maioria das vezes, a tutela legal de alguns desses interesses é flagrantemente conflitante com a proteção de outros. ${ }^{\text {"3 }}$

Este autor ressalta que a inflação jurídica - excesso de normas que, tornando praticamente impossível o seu acatamento pelos seus supostos destinatários e, sua efetiva aplicação pelo Poder Judiciário, acaba por impedir que o Direito positivo exerça suas funções controladoras e reguladoras é apenas uma das facetas das rupturas institucionais nas estruturas jurídicas e políticas legadas pelos Estados Liberal e Social. As outras rupturas, que têm como denominador comum o esvaziamento da soberania e da autonomia dos Estados nacionais, são a mundialização da economia, a desconcentração do aparelho estatal, a internacionalização do Estado, a desterritorialização e reorganização do espaço da produção, a fragmentação das atividades produtivas nos diferentes territórios e continentes e a expansão de um direito paralelo ao dos Estados, de natureza mercatória. ${ }^{4}$

Se, por um lado, o Estado ịa não consegue regular a sociedade através dos instrumentos jurídicos tradicionais - dada a redução crescente de seı poder de intervenção - por outro, precisa considerar $\mathrm{c}$ contexto econômico-financeirn internacional para tentar garantīi um mínimo de efetividade às suas normas.

Um exemplo que espelha essa crise do Estado e do Direito frente à economia globalizada é o que se refere à perda da diversidade biológica e genética existente no planeta, que "deve ser compreendida no contexto da passagem de um paradigma téc-

1. DERANI, Cristiane. Direito ambiental econômico. Sáo Paulo: Max Limonad, 1997, p. $28-29$.

2. GRAU, Eros Roberto. A ordem econômica na Constituiçăo de 1988: interpretação e críica. 2. ed., Sáo Paulo: RT, 1991, p. 20.

3. FARIA, José Eduardo (org.). Direito e globalização econômica: implicaçōes e perspectivas. 1. ed., São Paulo: Malheiros, 1998, p. 08-09.

4. FARIA, ibidem, p. 10-11. 
nico-econômico intensivo em recursos naturais para um outro baseado em informação e no uso crescente de ciência e tecnologia no processo produtivo. (...) A conjugação de crise ambiental e transformação da base técnico-científica mundial corresponde, por sua vez, a uma nova forina de 'politização da natureza', expressando a coexistência e o conflito de diferentes projetos e estratégias com respeito ao meio ambiente planetário e à biodiversidade em particular".5

\section{A proteção juríaica da biodiversidade}

A diversidade biológica refere-se à variedade e à variabilidade de formas de vida existentes na biosfera, incluindo a totalidade dos vegetais, dos animais e dos microorganismos, bem assim, dos ecossistemas nos quais eles se mantêm. Sua importância decorre não somente do fato de ser a fonte das matérias-primas de alimentos, habitações, vestimentas e medicamentos, mas também, porque dela deponde a manutenção das funções básicas dos ecossistemas: produção, decomposição e reciclagem de nutrientes; regeneração dos solos, regulação dos ciclos geobioquímicos e regulação climática. ${ }^{6}$
Por ocasião da Conferência das $\mathrm{Na}$ ções Unidas sobre Meio Ambiente e Desenvolvimento (CNUMAD), realizada no Rio de Janeiro em junho de 1992, foi ratificada por mais de cem países a Convenção da Diversidade Biológica $(\mathrm{CDB})$. $^{7}$ Os objetivos básicos da CDB são a conservação da biodiversidade nos níveis genético, específico e ecossistêmico; a sua utilização sustentável; a repartição justa e eqüitativa dos benefícios derivados do seu uso; o acesso adequado aos recursos genéticos e a transferência adequada de tecnologia. A Convenção também ressalva a soberania de cada Estado sobre os seus recursos biológicos, reconhece o papel das populações indígenas e das comunidades tradicionais e, a indispensável contribuição dos modos de vida desses grupos para a conservação dos recursos naturais, o que induz a uma redistribuição justa e eqüitativa pela eventual utilização de seus conhecimentos. ${ }^{8}$

Portanto, o acesso à biodiversidade e aos recursos genéticos constitui um instrumento de que os países em desenvolvimento podem se valer numa perspectiva estratégica, visando uma utilização economicamente viável, socialmente justa e ecologicamente prudente dos recursos naturais de que dispōem.

\section{ALBALGLI, Santa. Geopolitica da biodiversidade. Brasilia: Ibama, 1998, p. 17-18.}

6. VIEIRA, Paulo Freire. "Erosáo da biodiversidade e gestão patrimonial das interaçōes sociedade-natureza - oportunidades e riscos da inovaçăo biotecnológica". In O novo em direito ambiental. VARELLA, Marcelo Dias e BORGES, Roxana Cardoso B. (crg.), Belo Horizonte: Del Rey, 1998, p. 226-227.

7. A Convençăo sobre a Diversidade Biológica foi introduzida no direito brasileiro atràvés do Decreto Legislativo $n^{2} 02$, de 02 de fevereiro de 1994.

8. ALENCAR, Gisela S. de. Mudança ambiental global e a formação do regime para proteção da Biodiversidade. Dissertaçăo de Mestrado (UnB) apud RÊGO, Pairicia de Amorim. "Proteçāo juríica da diversidade biológica e culturar". In A proteçăo jurídica das florestas tropicais - anais do III congresso intemacional de direito ambiental. V. I, São Paulo: MESP, 1999, p. 327-328. 
A percepção do ser humano à necessidade da preservaçāo do meio ambien. te começou a ganhar corpo há pouco mais de duas décadas, acarretando uma alteração substancial nos paradigmas antes vigentes, que se limitavam a considerar o meio ambiente e os elementos que o compöem exclusivamente sob o enfoque econômico - como recursos naturais - e, as poucas normas que lhe garantiam alguma proteção tinham por objetivo unicamente evitar o seu esgotamento.

A Constituição brasileira de 1988 inovou ao destinar um capítulo exclusivo à matéria, inserindo o direito ao meio ambiente ecologicamente equilibrado dentre os direitos fundamentais, apesar de não elencálo no rol do art. 5\%, visto que "é direito fundamental também, aquele direito constitucionalmente atribuído, em cujo conteúdo se pode identificar uma coordenação de prescriçñes de direitos fundamentais básicos (liberdade, igualdade, fraternidade), e cuja realização revela-se na concretização total ou narcial desses direitos fundamentais". 9

Assinala CRISTIANE DERANI que os direitos fundamentais assumem dupla função na ordem jurídica contemporânea, pois "limitam as ações do Estado, ao mesmo tempo que corrigem o déficit da compreensão liberal dos direitos fundamentais e sua prática, isto é, ajustam a prática individual". Segundo a autora, a compreensão dos direitos fundamentais está pautada numa premissa essencial de que as liberdades individuais são indissociáveis das liberdades sociais ou coletivas. ${ }^{10}$

Ademais, o direito ao meio ambiente ecologicamente equilibrado implica diretamente o direito à vida, haja vista a complexa inter-relação entre o equilíbrio dc meio ambiente e a manutenção da biodiversidade.

A concepção unitária de meio ambiente abrange bens naturais e culturais e compreende, para JOSÉ AFONSO DA SILVA, "....a interação do conjunto de elementos naturais, artificiais e culturais que propiciam o desenvolvimento equilibrado da vida humana", ${ }^{11}$ aí incluídos todos os elementos que de alguma forma contribuam para a existência, a manutenção e o aprimoramento da vida e de sua qualidade, tais como o patrimônio natural, paisagístico, histórico ou artístico.

Nesta perspectiva, a Declaração do Meio Ambiente, adotada nela Conferência das Nações Unidas em Estocolmo, em junho de 1972, proclamou ter o homem o direito fundamental "à liberdade, à igualdade e ao desfrute de condições de vida adequada em um meio cuja qualidade lhe permite levar uma vida digna e gozar de bem-estar e tem a solene obrigação de proteger e melhorar esse meio para as gerações presentes e futuras...".

9. DERANI, ibidem, p. 219.

10. DERANI, ibidem, p. 220.

11. SILVA, José Afonso da. Direito ambiental constitucional. 2. ed., rev., Sấo Paulo: Malheiros, 1995, p. 02. 
A dignidade da pessoa humana, um dos fundamentos do Estado Democrático de Direito previsto no art. $1^{\circ}$, inc. III, da Constituição de 1988, compreende o proporcionar-se a todos uma sadia qualidade de vida, que somente será alcançada com a manutenção do meio ambiente ecologicamente equilibrado.

A proteção ambiental - que comporta a preservação dos elementos da natureza essenciais à vida humana e à manutenção do equilíbrio ecológico - visa, segundo JOSÉ AFONSO DA SILVA, tutelar a qualidade do meio ambiente em função da qualidade de vida, como uma forma de direito fundamental que caracteriza uma nova projeção do direito à vida pois, “...neste há de incluir-se a manutenção daquelas condições ambientais que são suportes da própria vida, e o ordenamento jurídico, a quem compete tutelar o interesse público, há que dar resposta coerente e eficaz a essa nova necessidade social"..12

A biodiversidade, por outro lado, foi acolhida pela Consitituição de 1 nog como um direito fundamental e bem jurídico a ser protegido, não somente no caput do art. 255 - visto que a garantia do meio ambiente ecologicamente equilibrado pressupõe e está condicionada à manutenção da biodiversidade -, mas também nos incs. II, IV e V do $\S 1^{\mathrm{o}}$ deste dispositivo, os quais estabelecem, respectivamente, incumbir ao Poder Público: a preservação da diversidade e da integridade do patrimônio genético do País; a exigência de estudo prévio de impacto ambiental para a instalação de obra ou atividade potencialmente causadora de significativa degradação ambiental; e o controle da produção, da comercialização e do emprego de técnicas, métodos e substâncias que comportem risco para a vida, a qualidade de vida e o meio ambiente.

No entanto, grupos hegemônicos vêm exercendo forte resistência ao cumprimento desse dever imposto pela Constituição. GUSTAVO TEPEDINO, em crítica veemente à tal situação, manifesta-se nos seguintes termos:

"Não parece demasiado afirmar que a cultura jurídica dominante criou duas Constituições. Há uma Constituição que vem sendo zelosamente aplicada, tomada em retalhos, disciplinadora de certos princípios da ordem e da manutenção do domínio econômico, da estruturaçāo do Estado e dos Poderes da República. É, de fato, o texto maior. E há outra Constituição, transformada numa espécic de carta de intençōes, que àssçưura us dizeitos indiōporisúi cis à ci. dadania e à dignidade do homem, tendo como princípio fundamental a erradicação da pobreza e a diminuição das desigualdades sociais. Esta foi reduzida, de fato, ao texto menor." 13

O direito ao meio ambiente ecologicamente equilibrado e o direito à preservação da diversidade e da integridade do patrimônio genético do país encontram-se, sem dúvida, no chamado "texto menor" da

12. SILVA, ibidem, p. 36 .

13. TEPEDINO, Gustavo. Temas de direito civil. Fio de Janeiro: Renovar, 1999, p. 301. 
Constituição de 1988, principalmente se forem considerados os condicionamentos que impõem à atividade econômica, tal como vem sendo praticada - sujeitando-a a alterações na sua lógica de funcionamento e, implicando uma mudança de paradigma da relação do ser humano com o seu meio.

Tramita há anos no Congresso Nacional um projeto de lei ${ }^{14}$ que regulamenta a CDB e o acesso aos recursos genéticos existentes em território nacional, com expressa previsão de instrumentos de proteção aos direitos intelectuais coletivos das comunidades detentoras do conhecimento tradicional utilizado pelas empresas de biotecnologia para o desenvolvimento de seus produtos e posterior patenteamento, tais como o consentimento informado e contraprestação tecnológica e financeira, por meio da realização de contratos de acesso, entre outros. ${ }^{15}$

A importância estratégica do reconhecimento de direitos intelectuais coletivus úc populaçũes indígenas e de comunidades tradicionais para a manutenção da biodiversidade é ressaltada por LAYMERT GARCIA SANTOS, nos seguintes termos:
"Vinculando proteção e acesso, os direitos intelectuais coletivos conferem conteúdo preciso ao exercicio da soberania nacional sobre os recursos biológi. cos. A soberania deixa de ser uma aspiração meramente retórica, na medida em que o Estado nacional se coloca. ria como a instância que garante as condições de conservaçāo e uso sustentável dos recursos, uma distribuição eqüitativa dos benefícios provenientes de sua utilização industrial, e, acima de tudo, a impossibilidade de sua aprcpriação exclusiva e monopolística, que lesaria as co. munidades do país. Protegendo as comunidades contra a biopirataria e re. gulando o acesso aos recursos biológicos, o Estado imporia limites à tentativa de apropriação da vida que, como já foi dito, deve acelerar a erosão da biodiver. sidade." 16

Porém, a velocidade com que vêm se dando a apropriação e a gestão economicista dos recursos genéticos disponíveis - com os riscos e ônus que lhe são inerentes sendo disseminados por toda a coletividade, encuanto que os dividendos decorrentes são usufruídos individualmente - tem atropelado as discussões, especialmente no que se refere à transferência de tecnologia no sentido Norte-Sul; aos efeitos desconhecidos

14. Projeto de lei $n^{\ominus} 306 / 95$, de autoria da senadora Marina Silva (PT/AC). 0 projeto foi modificado por um substitutivo do senador Osmar Dias (PSDB/PR) e aprovado no Senado Federal. O Poder Execufivo encaminhou ao Congresso Nacional outro projeto a respeito do tema.

15. Ver neste sentido, ARCANJO, Francisco Eugênio M. "Convençảo sobre diversidade biológica e projeto de lei do Senado $n^{\circledR} 306 /$ 95: soberania, propriedade e acesso aos recursos genéticos". In Anais do II congresso internacional de direito ambiental. São Paulo: IMESP, 1997, p. 37-64.

16. SANTOS, Laymert Garcia. "Propriedade intelectual ou direitos intelectuais coletivos?" In Biodiversidade e proteçăo do conhecimento de comunidades tradicionais. ARAÚJJO, Ana Valéria, e CAPOBIANCO, João Paulo (org.). Documentos do ISA n̊ 02, 1996, p. 22. 
de uma disseminação em grande escala de organismos geneticamente modificados (ogms); e, à regulamentação dos direitos das comunidades detentoras de conhecimentos tradicionais e dos titulares de "inovações" biotecnológicas.

\section{Biotecnologia e patentes}

Há menos de um século, algumas das atuais empresas transnacionais de biotecnologia lutavam contra os que defendiam a concessão de monopólios por meio de patentes. Atualmente, estas empresas pressionam governos para a obtenção de um sistema de patentes mais forte em todo o planeta, qualificando a inexistência de propriedade intelectual como uma barreira não-alfandegária, ao mesmo tempo em que desfraldam agressivamente a bandeira do livre comércio.

A razão para tal alteração de posicionamento repousa no fato de que tais cmpresas tornaram-se exportadoras de tecnologia. A exportação de tecnologia, aliada a $11 \mathrm{~m}$ rignroso sistema de patentes, dificulta a inovação e gera dependência econômica, tecnológica e científica nos países em desenvolvimento. O Banco Interamericano de Desenvolvimento (BID) produziu, em 1988, relatório demonstrando que a maioria das patentes de propriedade de estrangeiros nos países latino-americanos nunca é utilizada ali, servindo apenas para assegurar e monopolizar o fluxo de importaçôes. ${ }^{17}$

Mais da metade das espécies existentes na Terra encontram-se nas florestas tropicais úmidas, que ocupam apenas $6 \%$ (seis por cento) da superfície dos continentes. ${ }^{18}$ Não por acaso, os países detentores da chamada "megadiversidade" biológica situamse no hemisfério sul, encontram-se em desenvolvimento e são importadores de tecnologia.

\section{A lei brasileira de patentes}

A discussão pública a respeito da possibilidade de patenteamento, em outros países, de produtos desenvolvidos a partir de conhecimentos tradicionais e de plantas e animais coletados no Brasil, só veio à tona por ocasião da aprovaçāo, pelo Congresso Nacional, da chamada lei de patentes ou de propriedade industrial. Esta Lei, ${ }^{19}$ apesar de vedar o patenteamento de seres vivos - no todo ou em parte - previu o patenteamento de organismos geneticamente modificados (ogms) e de processos biotecnológicos oriundos de plantas e de animais, sem qualquer contraprestação financeira ou tecnológica aos detentores do conhecimento tradicional ou aos fornecedores da matéria-prima. ${ }^{20}$

\footnotetext{
17. HOBEELINK, Henk. "Patenteamento da vida". In Textos para debate $n^{2} 38$. AS-PTA - ^ssessoria e Serviços a Projetos em Agricultura Alternativa. Rio de Janeiro: Desktop, 1991, p. 02.

18. DEAN, Warren. A ferro e fogo: a história e a devastaçăc da mata atlântica brasileira. São Paulo: Companhia das Letras, 1996.

19. Lei Federal $n^{2} 9.279$, de 14 de maio de 1996.

20. Ver neste sentido, CAPPELLI, Silvia. "Biodiversidade, aspectos jurídicos: lei de propriedade industrial sob a ótica ambiental necessidade de contraprestaçăo económica e tecnológica ao pais farnecedor de matéria-prima para a biotecnologia". In Anais do II congresso internacional de direito ambiental. Säo Paulo: IMESP, 1997, p. 293-303.
} 
Neste sentido, estão sendo veiculados pela imprensa e em revistas especializadas números cada vez maiores de casos de envio ilegal de plantas e animais coletados em florestas brasileiras para empresas de "bioprospeç̧ão" ou bancos de germoplasma privados localizados em centros de pesquisa no exterior, ${ }^{21}$ não obstante o rigor do Decreto n⿳9 98.830, de 15 de janeiro de 1990, que dispõe sobre a coleta, por estrangeiros, de dados e materiais científicos no Brasil. ${ }^{22}$

A par disso, a aprovação da lei de patentes muito antes do fim do prazo que o Brasil possuía (2001) para reconhecer o patenteamento de biotecnologias deve-se, em grande parte, à pressão exercida sobre o governo brasileiro pelos países que dominam a Organização Mundial do Comércio (OMC), especiaimente os Estados Unidos (que não ratificaram a $\mathrm{CDB}$ ), visto que não estavam protegidas pelo antigo Código de Patentes ${ }^{23}$ as inovações tecnológicas nas áreas química, farmacêutica e alimentícia. Trata-se de uma das exigências áo acordo firmado pelo Brasil junto à $\mathrm{OMC}$, referente aos direitos de propriedade intelectual relacionados ao comércio. ${ }^{24}$

De acordo com os termos da lei brasileira de propriedade industrial, é “patenteável a invenção que atenda aos requisitos de novidade, atividade inventi- va e aplicação industrial" (art. $8^{\text {9) }}$, que vigora por vinte ou quinze anos (patente de invenção e de utilidade, respectivamente), contados da data de depósito (art. 40). Novo, por outro lado, é tudo aquilo que não se encontra no domínio público.

O titular da patente, segundo o art. 42 desta lei, tem o direito de "impedir terceiro, sem o seu consentimento, de produzir, usar, colocar à venda, vender ou importar" o produto ou o processo e o produto dele obtido. $\mathrm{O}$ infrator fica sujeito aos crimes contra as patentes (arts. 183 e 184), com pena de detenção de três meses a um ano ou multa, bem assim, às ações cabíveis no âmbito civil.

A aplicação de dispositivos semelhantes vem ocorrendo nos Estados Unidos, em casos de utilização de sementes geneticamente modificadas cuja patente pertence a empresas de biotecnologia (que tairibém comercializam defensivos agrícolas e adubos) e que, conforme costume tradicional dos agricultores, são guardadas para plantio na safra seguintitc. Nấ Índia c em outros países asiáticos nos quais a reserva das melhores sementes constitui uma tradição milenar, que diz respeito à identidade cultural daqueles povos, têm havido reaçōes de agricultores, entidades socioambientais e da comunidade científica contra a imposição dessas regras.

21. FON, Aritonio Carlos. "O ataque dos biopiratas: como as riquezas da Amazónia estão sendo saqueadas pelos piratas da biodiversidade". Revista Terra. 90. ed., Săo Paulo, n 10, p. 58-63, out/1999. Neste mesmo sentido, Seminário internacional sobre direito da biodiversidade. Revista do Centro de Estudos Judiciários da Justiça Federal. Brasilia, n² 08, mai-ago/1999.

22. Este decreto foi regulamentado pela Portaria $n^{2} 55$, de 14 de março de 1990, do Ministério da Ciência e Tecnologia.

23. Lei Federal $n^{2} 5.772$, de 21 de dezembro de 1971.

24. Este acordo é conhecido pela sigla TRIPS e foi incorporado ao direito interno por meio do Decreto $n^{2} 1.355$, de 30 de dezembro de 1994, que promulgou a ata final da rodada Uruguai de negociaçōes comerciais multilaterais do GATT. 
No Brasil, tal situaçāo ainda nāo ocorreu em razāo de uma decisāo proferida em ação civil pública, ${ }^{25}$ que condiciona a liberação do plantio e da comercialização de sementes de soja geneticamente modificadas e devidamente patenteadas, à realização de Estudo Prévio de Impacto Ambiental - EPIA, às expensas da empresa de biotecnologia que as desenvolveu. ${ }^{26}$

\section{Conclusōes}

O Brasil é signatário da Convenção da Diversidade Biológica (CDB) e do tratado firmado junto à Organização Mundial do Comércio (OMC) que se refere aos direitos de propriedade intelectual relacionados com o comércio (TRIPS). Estas convenções têm objetivos antagônicos e conflitivos entre si.

A implementação da CDB no Brasil deve ser feita por meio de uma lei de acesso aos recursos genéticos e outra, a respeito da conservação da biodiversidade, nenhuma das duas já editada.

Já o acordo firmado junto à $\mathrm{OMC}$ teve uma de suas exigências devidamente cumprida com a edição da lei de patentes, de modo que estão protegidos os direitos de propriedade intelectual sobre as inovações tecnológicas nas áreas química, farmacêutica e alimentícia.

Dessa forma, verifica-se que, apesar de as patentes sobre organismos genetica- mente modificados e sobre processos biotecnológicos encontrarem-se protegidas pelo ordenamento jurídico brasileiro, áinda nāo há amparo jurídico específico no que tange à contraprestação finaniceira $e$ tecnológica, às comunidades locais e populaçōes indígenas detentoras de conhecimentos tradicionais utilizados em processos biotecnológicos patenteados.

A perpetuação desta situação, além de acarretar o descumprimeritu de uma convenção internacional devidamente ratificada e, do direito fundamental ao meio ambiente ecologicamente equilibrado, tende a estimular a biopirataria e a consolidar um sistema de proteção da propriedade intelectual que nenhum benefício traz ao país, que tem de pagar royalties por produtos e processos biotecnológicos originados de conhecimentos tradicionais relativos a plantas e animais que compōem os seus recursos biológicos, sobre os quais detêm soberania.

Há também um incremenco da erosão da biodiversidade e de sociodiversidade, ao mesmo tempo em que se acentua a dependência econômica, científica e tecnológica aos países desenvolvidos, o que contribui para o aumento da pobreza, da desigualdade e da injustiça social.

\section{Referências bibliográficas}

ALBALGLI, Sarita. Geopolítica da biodiversidade. Brasília: Ibama, 1998.

25. A ação foi proposta pelo Greenpeace e pelo Instituto de Defesa do Consumidor - IDEC e está em andamento na Justiça Federal do Distrito Federal.

26. A introduçăo de produtos geneticamente modificados em território brasileiro é sujeita acs termos da Lei Federal $n^{2} 8.974$, de 05 de janeiro de 1995 - Lei Nacional de Biossegurança. 
ARAÚJO, Ana Valéria e CAPOBIANCO, Joâo Paulo R. (org.). Biodiversidade e proteção do conhecinento de comunidades tredicicnais. São Paulo: Instituto Socioambiental, 1995.

AS-PTA - Assessoria e Serviços a Projetos em Agricultura Alternativa. Textos jara debate n³8. Rio de Janeiro: Desktop, 1991.

Congresso Internacional de Direito Ambiental (2., 1997, São Paulo). Anais: a proteção jurídica das florestas tropicais. São Paulo: IMESP 1997.

Congresso Internacional de Direito Ambiental (3., 1999, São Paulo). Anais: a proteção jurídica das florestas tropicais. Sāo Paulo: IMESP, 1999.

DEAN, Warrein. A ferro e fogo: a história e a devasta. çāo da mata atlântica brasileira. São Paulo: Com. panhia das Letras, 1996.

DERANI, Cristiane. Direito ambiental econômico. São Paulo: Max Limonad, 1997.

FARIA, José Eduardo (org.). Direito e globalização econômica: implicações e perspectivas. 1. ed., São Paulo: Malheiros, 1998.

FIGUEIREDO, Guilherme José Purvin de (org.). Temas de direito ambiental e urbanístico. São Paulo: Max Limonad, 1998.

FIORILLO, Celso A. Pacheco e RODRIGUES, Marcelo Abelha. Direito ambiental e patrimônio gené. tico. Belo Horizonte: Del Rey, 1996.

- e DIAFÉRIA, Adriana. Biodiversidade e patrimônio genético no direito ambiental brasileiro. São Paulo: Max Limonad, 1999.

FON, Antonio Carlos. O ataque dos biopiratas: como as riquezas da Amazônia estão sendo saqueadas pelos piratas da biodiversidade.

Revista Terra: São Paulo, ed. 90, n²10, p. 58-63, out. 1999.

FREITAS, Vladimir Passos de (org.). Direito ambiental em evoluçāo. Curitiba: Juruá, 1998.

GRAU, Eros Roberto. A ordem econômica na Constituição de 1988: interpretação e crítica. 2. ed., São Paulo: RT, 1991.

LEITE, Eduardo de Oliveira. A monografia jurídica. 3. ed., rev., São Paulo: RT, 1997.

MACHADO, Paulo Affonso Leme. Direito ambiental brasileiro. 6. cd., rev., São Paulo: Malheiros, 1996.

Revista do Centro de Estudos Judiciários do Conselho da Justiça Federal. Seminário internacional so. bre direito da biodiversidade. Brasília: CJF, no 08, mai-ago/1999.

SILVA, José Afonso da. Curso de direito constitucional positivo. 5. ed., rev., São Paulo: RT, 1989.

Direito ambiental constitucional. 2. ed., rev., São Paulo: Malheiros, 1995.

SOUZA Fํㅜ, Carlos Frederico Marés de. Bens culturais e proteçāo jurídica. Porto Alegre: Unidade Editorial, 1997.

. O renascer das povos indígenas para o direito. Curitiba: Juruá, 1998.

TEPEDiNO, Gustavo. Temas de direito civil. Rio de Janeiro: Renovar, 1999.

VARELLA, Marcelo Dias (org.). O novo em direito ambiental. Belo Horizonte: Del Rey, 1998. 